\title{
Relaciones hispano-paraguayas durante la Primera Guerra Mundial: el «Banco de España y Paraguay» en Asunción*/
}

\author{
Spanish-Paraguayan Relations during First World War: \\ the «Bank of Spain and Paraguay» in Asunción
}

\author{
Gabriela Dalla-Corte Caballero
}

Universitat de Barcelona

En 1895 el migrante español Camilo Pérez y Pérez decidió establecerse en la capital de la República del Paraguay, Asunción, y se encargó de fomentar las relaciones internacionales a través de la creación del «Banco de España y Paraguay». También fue nombrado corresponsal de la Revista Comercial Iberoamericana Mercurio, y delegado de la «Casa de América», ambas entidades americanistas barcelonesas. El proyecto llegó a su fin pocos años después del fin de la Primera Guerra, y la correspondencia se conserva hoy día en el Pabellón de la República de la Universidad de Barcelona.

Palabras Claves: Paraguay; Barcelona; España; Economía; Bancos; Siglo XX.

In 1895, Spanish migrant Camilo Pérez y Pérez decided to settle in Asunción, capital of the Republic of Paraguay, and was responsible for encouraging international relations through the creation of the "Bank of Spain and Paraguay». He was also named Revista Comercial Iberoamericana Mercurio correspondent and «Casa de América» representative, both Americanist entities established in Barcelona. The project came to an end few years later after World War I, and correspondence is nowadays preserved in the Pavilion of the Republic at University of Barcelona.

KEYwords: Paraguay; Barcelona; Spain; Economy; Bancs; Twentieth Century.

* Este trabajo ha sido realizado en el marco del proyecto de investigación Donde la política no alcanza: el reto de diplomáticos, cónsules y agentes culturales en la renovación de las relaciones entre España e Iberoamérica, 1880-1939 (HAR2014-59250-R), financiado por el Ministerio de Economía y Competitividad. Agradezco las sugerencias y comentarios de los/las evaluadores/as de este artículo. 


\section{Introducción}

A inicios del siglo XX España aspiró a recuperar sus relaciones diplomáticas con la República del Paraguay, país que sufría una difícil situación poblacional, económica y financiera como consecuencia de la guerra de la Triple Alianza llevada adelante por los ejércitos de Argentina, Brasil y Uruguay (1865-1870). La Casa de América de Barcelona, entidad privada inaugurada en abril de 1911, acompañó este proceso de reorganización internacional y generó nuevos dispositivos de intercambio mercantil y comercial con Paraguay. El objetivo de este artículo es analizar el proyecto gestado por esta asociación americanista catalana al establecer relaciones directas entre su secretario, el joven abogado Rafael Vehils i GrauBolívar, y el español Camilo Pérez y Pérez, este último migrado a la ciudad de Asunción a finales del siglo XIX, una práctica muy habitual en la época, ${ }^{1}$ y que en junio de 1914 aceptó convertirse en delegado. ${ }^{2}$

La tarea de Pérez fue informar, tanto de manera oficial como confidencial, sobre la situación política, económica y social de su país receptor, y las posibilidades de fortalecer a las empresas españolas que buscaban fomentar los vínculos comerciales con Paraguay. Parte de esta información le llegó a Vehils, quien en 1913 se encargó de elaborar un libro sobre los fundamentos del americanismo español, con especificidades estrictamente catalanas, que fue publicado en la provincia argentina de Corrientes, ${ }^{3}$ y que dos años después, en 1915, le llevaría a elaborar un memorándum reservado sobre el fomento de las relaciones de España con las repúblicas visitadas. ${ }^{4}$ Las cartas que se escribieron Vehils y Pérez en esos años, constituyen una importante fuente de información, ya que nos permiten reconstruir, por ejemplo, el mecanismo utilizado por la Casa de América para reorganizar sus relaciones con las antiguas colonias, pero en especial la confianza suscitada por la visita oficial que Rafael Vehils hizo a Asunción en las navidades de 1912, que le permitió conocer a Pérez y mantener la correspondencia durante más de una década. Esta documentación fue conservada en el Archivo General de la Casa de América, ubicado entonces en la propiedad de la familia Cambó de la Vía Laietana n. ${ }^{\circ} 28$, de Barcelona. En la década

1 Naranjo Orovio, 2010.

2 Casa de América de Barcelona, Archivo General (en adelante, CA-AG), caja 12.3 (enviado), Rafael Vehils (Barcelona) a Camilo Pérez (Asunción del Paraguay), 23 de abril de 1914.

3 Vehils, 1913

4 Vehils, 1915. 
de 1980, los documentos que analizamos fueron trasladados al Pabellón de la República de la Universidad de Barcelona. ${ }^{5}$

Las fuentes documentales conservadas en este Pabellón forman parte del objetivo de este artículo, que está organizado en los siguientes apartados: el primero se centra en el viaje que Vehils y Antonio B. Pont hicieron en las navidades de 1912 a Asunción del Paraguay, donde contactaron con Pérez y donde implementaron parte del proyecto comercial y financiero de la Casa de América de Barcelona. El segundo apartado se vuelca en la descripción de las actividades llevadas adelante por Pérez al aceptar ser delegado de la Casa y corresponsal del órgano de propaganda de esa entidad catalana, la Revista Comercial Iberoamericana Mercurio, que funcionaba desde diciembre de $1901 .{ }^{6}$ El tercer apartado analiza el contenido de las cartas que se escribieron Vehils y Pérez durante la Primera Guerra Mundial, en el marco de la creación del «Banco de España y Paraguay» con sede en la ciudad de Asunción. Cerramos el trabajo con la transformación producida en el periodo de entreguerras en el Paraguay, hecho que impulsó la presencia financiera británica y estadounidense y acompañó la decisión de Pérez de abandonar su condición de delegado de la Casa de América y corresponsal de la revista Mercurio, además de clausurar las puertas de su banco, tanto hispano como paraguayo.

\section{Misión Oficial en Paraguay: Rafael Vehils en el «Club Mbigua»}

Los diseñadores de la original entidad americanista catalana fueron los propios miembros responsables de la Revista Comercial Iberoamericana Mercurio. Esta publicación quincenal nació para divulgar la producción económica y comercial desde diciembre de 1901. Desde su inicio, Mercurio habilitó una novedosa información sobre la situación paraguaya, y en 1902 sus responsables José Puigdollers Macià, Frederic Rahola Trèmols (conocido por su trabajo como secretario del Fomento del Trabajo Nacional), ${ }^{7}$ y el artista Pedro Casas Abarca, decidieron publicar un primer artículo sobre el viaje que el catalán Jorge Bach hizo por los ríos Paraná y Paraguay, afirmando que los religiosos estaban obligados a unir matrimonialmente a más de

5 Dalla-Corte Caballero, 2013.

6 Dalla-Corte Caballero, 2012.

7 Sellés i Quintana, 2002. 
mil parejas en una sola bendición por el desastre poblacional que dejó la guerra de la Triple Alianza. Esa guerra contra Argentina, Brasil y Paraguay había destrozado a la sociedad paraguaya, mientras «el pequeño comercio y las pequeñas industrias están en manos de mujeres, muy varoniles, por cierto». ${ }^{8}$

Ese fue el primer dato que apareció en las páginas de Mercurio, la revista catalana interesada en forjar la relación comercial con Paraguay y que representaba precisamente el americanismo catalanista. ${ }^{9}$ En febrero de 1910, Juan Silvano Godoi, el entonces director general de la Biblioteca Nacional de Asunción del Paraguay, decidió enviar a esta revista los escasos libros históricos existentes en ese desconocido país. También solicitó a la revista que le enviase libros elaborados en Barcelona para que pudiesen leer «los hombres de letras de la República». ${ }^{10}$ Pocos meses después fue el español Viriato Díaz-Pérez — por entonces director del Museo y Archivo Nacional del Paraguay y responsable de la redacción de la revista de este instituto, además de secretario del Centro Español en Asunción y antiguo cónsul general del Paraguay en Madrid - ${ }^{11}$ quien le agradeció al joven Vehils el envío de diversas obras publicadas en España, junto al informe de la posible creación de una «Biblioteca de América» en el seno de una futura Casa de América de Barcelona. Díaz-Pérez se encargó de hacer llegar a Vehils el texto titulado «Las Conferencias de Blasco Ibáñez en el Paraguay», afirmando que su esperanza era colaborar con su patria de origen, escribir para la revista Mercurio, y aportar datos estadísticos del comercio paraguayo a la futura Casa de América barcelonesa. Esta decisión coincidió con la celebración de las independencias hispanoamericanas, que ayudó a las nuevas entidades españolas a sostener, en la distancia, las relaciones con las antiguas colonias y fomentar ese imaginario que fortalecería la restauración española. ${ }^{12}$ Ese hispanoamericanismo formó parte de un movimiento cultural que ejerció una importante presión sobre el nacionalismo español. ${ }^{13} \mathrm{Y}$ como escribiera Díaz-Pérez, las auras podían llegar a la madre patria si estaban saturadas de buenos deseos, y él los

8 Bach, 1902.

9 Ucelay-Da Cal, 2003. de 1910.

10 CA-AG, 12.2, Juan Silvano Godoi (Asunción) a Rafael Vehils (Barcelona), 11 de febrero

11 Pla, 1993.

12 Marcilhacy, 2010

13 Sepúlveda, 2005. 
ayudaría desde la casa solariega «en la que no todo es oro, progreso y libertad». ${ }^{14}$

En abril de 1911, la Casa de América de Barcelona abrió sus puertas de la mano de empresarios locales, junto a enriquecidos comerciantes que habían abandonado Puerto Rico y Cuba a finales del siglo XIX. La estrategia de esta Casa fue unir publicidad, cultura y economía, vinculando así su condición de asociación internacional iberoamericana con la renovación de las relaciones mantenidas por España con sus antiguas colonias. En el caso del Paraguay, la primera estrategia fue solicitar a Alejandro Morillo y Doremus, el cónsul general de la República del Paraguay establecido en la ciudad condal, que les hiciese llegar los datos de importación y exportación paraguayos, los valores cotizados, los impuestos y fianzas que se exigían a los viajantes de comercio, y una información lo más amplia posible sobre las expresiones artísticas y culturales del país. En ese momento, Morillo y Doremus solo pudo contestar que el gobierno del Paraguay nunca había proporcionado la información solicitada y que incluso carecía de ejemplares del himno nacional..$^{15}$

La Casa de América — entidad presidida en esos años por el uruguayo José Viñas Muxí y por Luis Riera y Soler, aunque de manera transitoria- se dirigió a Valentín F. Corcova, el cónsul del Paraguay establecido en Santander, para solicitarle el envío de datos estadísticos de la exportación española al Paraguay, para que la Cámara de Relaciones Comerciales de Barcelona pudiese confeccionar una estadística exacta de las condiciones de exportación de España hacia aquel país. El mencionado padrón debía rectificar, según los responsables de la Casa de América, los errores en que solían incurrir las estadísticas oficiales elaboradas en Madrid, las cuales señalaban «las cifras más bajas de la realidad». Es significativo el hecho de que la sugerencia de acudir a Valentín F. Corcova proviniese precisamente del responsable del Consulado General de Paraguay en Madrid, Fernando Pignet. ${ }^{16}$

La original correspondencia diseñada por la Casa barcelonesa facilitó la organización de una comisión oficial en pleno año 1912, cuya labor

14 CA-AG, 12.2, Viriato Díaz-Pérez (Asunción) a Rafael Vehils (Barcelona), 11 de febrero de 1910.

15 CA-AG, 12.2, Alejandro Morillo y Doremus (Barcelona) a Rafael Vehils (Barcelona), 10 de noviembre de 1911; 3 de enero de 1912; 14 de febrero de 1912 y 5 de octubre de 1912. de 1912.

16 CA-AG, 12.3, Casa de América (Barcelona) a Valentín F. Corcova (Santander), 10 de mayo 
principal era contactar con los empresarios españoles establecidos en Paraguay, vincularse con centros y sociedades españolas y con la prensa local, y analizar los mercados de la América del Sur. El Ministerio de Relaciones Exteriores del Paraguay aceptó el proyecto e hizo llegar a los cónsules establecidos en Argentina, Uruguay y Paraguay las instrucciones básicas acerca de las tareas a asumir en el momento en que recibiesen a los miembros de una novedosa «Misión Comercial» conformada por los catalanes Rafael Vehils y Antonio B. Pont. ${ }^{17}$

En efecto, el 7 de noviembre de 1912 Vehils partió de Barcelona en compañía de Pont, utilizando el vapor «Infanta Isabel», y desembarcando poco después en Montevideo. ${ }^{18}$ Mariano Fábregas Sotelo, el cónsul de España en Paraguay, gestionó las franquicias aduaneras y la rebaja de los pasajes de ambos viajeros para que pudiesen trasladarse a Asunción. Tiempo después, Fábregas Sotelo utilizó una de sus cartas para referirse a la trascendencia del proyecto de expansión del americanismo español en sus antiguas colonias, en particular en la desconocida República del Paraguay. ${ }^{19}$

Los delegados de la Casa barcelonesa llegaron a Asunción en diciembre de 1912. Díaz-Pérez decidió llevarlos al Club Nacional de Regatas llamado «El Mbigua», entidad hoy vigente, donde pudieron conocer a un importante número de empresarios españoles, entre ellos a los dueños de la «Enrique Clari Hermanos», que provenían de la ciudad de Manresa y que en Paraguay se dedicaban a la construcción de edificios en calidad de «obras de arte moderno», así como a Camilo Pérez, el director de la «Pérez y Sanjurjo S.A.». Este último les señaló que la persona indicada para gestionar el proyecto hispano-paraguayo era el intelectual Carlos R. Santos. ${ }^{20}$

De regreso de su viaje al Paraguay, Rafael Vehils sugirió nombrar al paraguayo Carlos R. Santos como delegado de la Casa de América ya que se trataba de un erudito que conocía perfectamente la situación paraguaya. ${ }^{21}$

17 CA-AG, 12.2, Emilio Payoli (Asunción) a Casa de América (Barcelona), 20 de diciembre de 1912.

18 CA-AG, 14 (notas y documentos generales de la Casa de América para sus diversos destinatarios en calidad de delegados), «Varios destinatarios nacional e internacional» (mimeo).

19 CA-AG, 17.3 (fuentes generales sobre administraciones públicas), Mariano Fábregas Sotelo (Asunción) a Luis Riera y Soler (Barcelona), 6 de setiembre de 1912; CA-AG, 17.4 (fuentes generales sobre administraciones públicas), 19 de enero de 1913.

20 CA-AG, 12.2, Viriato Díaz-Pérez (Asunción) a José Viñas Muxí (Barcelona), 4 de noviembre de 1912 .

21 CA-AG, 12.3, Casa de América (Barcelona) a Carlos R. Santos (Asunción), 23 de abril de 1914. 
Hablamos del autor del libro La República del Paraguay, que fue publicado en Asunción en el año 1897 gracias a la labor ejercida por los Talleres Nacionales de H. Kraus. En dicho libro, Santos había abordado diferentes temas: límites geográficos paraguayos, clasificación y composición del suelo, hidrografía y clima, producción vegetal, animal y mineral, así como la organización política, las actividades económicas y la importancia concedida a la «naturalización» de la población establecida en Paraguay después de la guerra de la Triple Alianza, entre la que aparecía un buen número de migrantes españoles (entre ellos, catalanes) ${ }^{22}$ e italianos. ${ }^{23}$ Sin embargo, Santos no respondió. Por ello, el entonces presidente de la Casa de América, el marqués de Marianao, Salvador Samá y Torrents, aceptó la sugerencia de Vehils de nombrar como delegado al español Pérez, quien por entonces se desempeñaba como presidente de la Sociedad Española de Socorros Mutuos de Asunción. ${ }^{24}$

Documentos históricos de esta naturaleza nos muestran el trabajo, de carácter honorífico, que asumieron los delegados nombrados por la Casa de América al aportar información oficial o confidencial a los empresarios de la ciudad de Barcelona, y al establecer un contacto más directo con las empresas esparcidas en el mundo. Hablamos de españoles que en su juventud habían abandonado España, su patria de origen, y se habían radicado en algún país de América. La idea de la Casa barcelonesa era obtener de ellos una amplia información sobre la situación económica y sobre las posibilidades comerciales y financieras que permitiesen una nueva y original alianza entre Cataluña y los jóvenes gobiernos americanos. Los delegados debían ser «personas activas que puedan presentar a la corporación los servicios que esta necesita». Este fue el mensaje que acompañó a todas las cartas formales que la asociación internacional catalana les hizo llegar a las personas con las cuales los empresarios catalanes pretendían mantener un contacto asiduo en virtud de su prestigio, y en especial por su «simpatía por nuestra obra». ${ }^{25}$ Como vemos, la Casa de América de Barcelona propuso este proyecto a diversas personas establecidas en Paraguay, entre ellas un buen número de catalanes, pero finalmente consiguió nombrar a Pérez como delegado de la entidad.

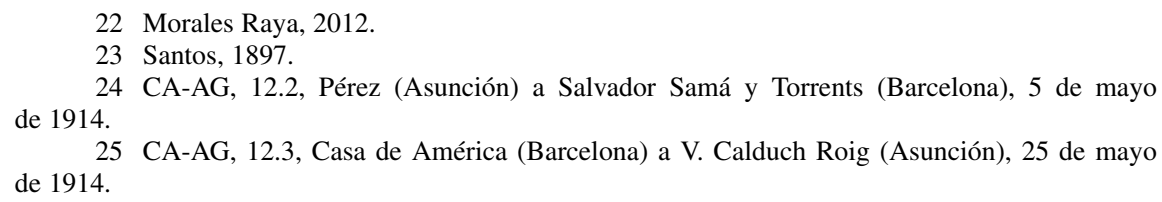

24 CA-AG, 12.2, Pérez (Asunción) a Salvador Samá y Torrents (Barcelona), 5 de mayo 25 CA-AG, 12.3, Casa de América (Barcelona) a V. Calduch Roig (Asunción), 25 de mayo de 1914. 


\section{Delegado y periodista español en Asunción}

La primera información que Vehils envió a su delegado Pérez fue que la Unión de Asociaciones Internacionales había decidido incorporar a la Casa barcelonesa en calidad de miembro efectivo durante la reunión que se convocaría en Bruselas el 29 de junio de 1913. Según Vehils, la corporación catalana era la única institución europea que pretendía llevar adelante la organización internacional del «viejo mundo» con el «nuevo mundo». Esta singular actuación permitía a sus responsables designar a delegados, en general de origen español, que se hubiesen radicado en el continente americano y que hubiesen demostrado su interés por recuperar los vínculos mercantiles con su patria de origen. Por ello, Vehils le adjudicó a Pérez el derecho a utilizar el membrete «Casa de América, Asociación Internacional Iberoamericana, Delegación en la República del Paraguay». ${ }^{26}$

Antes de aceptar su nombramiento como delegado de la Casa, Pérez le solicitó a Vehils que le enviara las instrucciones sobre lo que se esperaba de él, aseverando que procuraría «interpretar sus deseos dentro de mis escasos conocimientos, pero sí con todo el calor que me merece la empresa patriótica». ${ }^{27}$ En ese contexto, Camilo decidió informar de su condición de delegado de la Casa de América barcelonesa al Ministerio de Relaciones Exteriores de Paraguay; a E. Gunter, el presidente de la Cámara de Comercio de Asunción, quien fue representado por su secretario José Rodríguez Alcalá; y a Ernesto Egusquiza, el intendente municipal de Asunción, que había sido designado por el presidente Eduardo Schaerer, quien fue representado por su secretario, Eduardo Recalde. ${ }^{28}$

Pérez también decidió consultar la opinión del intelectual y político paraguayo Gualberto Cardús Huertas, autor de interesantes textos sobre el Paraguay, ${ }^{29}$ además de doctor y profesor de Derecho y Ciencias Sociales por la Universidad Nacional de Asunción (UNA). Cardús le sugirió que aceptara incorporarse como delegado de la Casa barcelonesa, para ampliar así su propia trayectoria asociativa, cultural y económica desempeñada en Asunción, y para obtener recursos de todo tipo que sirviesen para impulsar a la República del Paraguay. ${ }^{30}$

26 CA-AG, 12.3, Vehils (Barcelona) a Pérez (Asunción), 24 de julio de 1914; 2 de agosto de 1915 y 21 de agosto de 1915.

27 CA-AG, 12.2, Pérez (Asunción) a Vehils (Barcelona), 16 de junio de 1914.

28 Verón, 2011.

29 Cardús Huertas, 1911.

30 CA-AG, 12.2, Pérez (Asunción) a Vehils (Barcelona), 23 de setiembre de 1914; 30 de setiembre de 1914 y 5 de octubre de 1914. 
Es importante señalar a qué se refería Cardús Huerta al describir la trayectoria de Camilo Pérez en Paraguay: a inicios del siglo XX, Pérez había sido nombrado vicecónsul honorario de España en Paraguay; fue también miembro del directorio, presidente interino de las Oficinas de Cambios del Estado paraguayo, y miembro de las siguientes entidades: la «Sociedad de Seguros contra todo riesgo La Paraguaya»; la «Compañía Paraguaya de Frigorífico y Carnes Conservadas», la primera en su género en Paraguay, de la que fue fundador; el Honorable Consejo Municipal de la capital de la República del Paraguay; vocal del Ministerio de Hacienda por elección popular; consejero de la Sucursal del Banco de España y América establecida en Asunción; y miembro del directorio de la Cámara y Bolsa de Comercio de Paraguay. En 1914 Pérez también presidía el Banco de España y Paraguay, cuyo objetivo era vincular el intercambio comercial entre ambos países. ${ }^{31}$

A nivel social, en ese año se desempeñaba como presidente de la Sociedad Española de Socorros Mutuos, la entidad con personería jurídica que había sido fundada en Asunción el 9 de marzo de 1873 y reconocida por el gobierno paraguayo el 21 de mayo de 1877. En febrero de 1914 nuestro personaje había acordado crear junto a su colega Antonio Sanjurjo la empresa de exportación e importación llamada «Pérez y Sanjurjo S.A.», que quedó ubicada en la calle 25 de Mayo n. ${ }^{\circ}$ 180-184, de Asunción. En cuanto a su organización, Sanjurjo y Pérez se encargaron de la presidencia y la dirección, respectivamente, asumiendo un total de 75 acciones. El resto de acciones ( $25 \%$ ) quedó en manos de los siguientes comerciantes españoles (entre los que encontramos un buen número de catalanes): Andrés del Val, José Domingo Gómez Sanjurjo, José Manuel Balteiro, Francisco Di Lascio, Antonio Estragués, José Mayans y su hijo José Antonio. De acuerdo con los datos ofrecidos por el propio Camilo Pérez, esta nueva sociedad anónima tenía como objetivo la explotación de negocios y operaciones mercantiles de exportación e importación. Su texto fue publicado en Asunción por el diario Liberal, el órgano del Partido Liberal del Paraguay. ${ }^{32}$ Pérez señaló que su reciente sociedad anónima conformada con Antonio Sanjurjo había sido legalizada en Londres. ${ }^{33}$

31 Rahi, 1997. de 1914.

32 CA-AG, 12.2, «Estatutos de la Pérez y Sanjurjo S.A.», Liberal, Año II, 27 de febrero 33 CA-AG, 12.2, Pérez (Asunción) a Salvador Samá y Torrents (Barcelona), 26 de octubre de 1914. 
Rafael Vehils, en calidad de director de la Casa de América, decidió comunicarle el primer gran ensayo que habían decidido ejecutar para formalizar las relaciones con el Paraguay. El empresario Fábregas Sotelo había llegado a Barcelona con destino a Constantinopla, informándoles sobre el encargo oficioso que le había hecho el gobierno paraguayo de gestar en Barcelona un empréstito análogo al que había contratado el 30 de enero de ese mismo año el ministro de Hacienda paraguayo, Gerónimo Zubizarreta, con «The Paraguayan Corporation» del estado de Delaware de los Estados Unidos de América. También hizo llegar a Pérez el principio de que no era el mejor momento para llevar adelante proyectos de esta índole, pero que en el futuro podían encontrar mejores auspicios. Ese momento, según él, estaba caracterizado por la progresiva intensidad de las salidas del ahorro español que afectaba al capital, y por los conflictos bélicos de carácter internacional que perjudicaban a las cuentas corrientes y a los depósitos bancarios. Vehils concluyó que lo más urgente era recibir de Pérez una copia íntegra del contrato firmado entre el gobierno paraguayo y «The Paraguayan Corporation»..$^{34}$

El entonces director de la Casa se comprometió a contactar a Pérez con el ministro de Estado de España; a informarle sobre la exportación de productos españoles al Paraguay; a editar sus informes trimestrales en las páginas de Mercurio; y a hacer circular la copia de los mensajes presidenciales del Paraguay, entre ellos el del presidente Eduardo Schaerer. También le indicó sobre la llegada de la primera madera paraguaya a Barcelona: Rahola Trèmols, en calidad de consejero de la Casa de América y director de la revista Mercurio, se encargó de recibir el primer envío conformado por diez vigas de cedro y cinco de peteribí que había aceptado transportar la «Compañía Trasatlántica». ${ }^{35}$ En sus cartas, Vehils también se refirió al peso de la guerra internacional, que impedía aumentar la importación, y le señaló a Pérez que la Casa barcelonesa no podía gestionar ningún negocio económico, ya que era una sociedad sin fines de lucro, sin interés público, ni comercial, ni particular. ${ }^{36}$

Con todo esto en marcha, la Asociación Internacional Iberoamericana organizó un repertorio iconográfico de delegados designados en América. En dicho repertorio aparece la imagen fotográfica de Pérez que este último

34 CA-AG, 12.3, Vehils (Barcelona) a Pérez (Asunción), 9 de octubre de 1914.

35 Rodrigo Alharilla, 2001; Martínez Riaza, 2003. de 1915 .

36 CA-AG, 12.3, Vehils (Barcelona) a Pérez (Asunción), 12 de julio de 1915 y 3 de agosto 
RELACIONES HISPANO-PARAGUAYAS DURANTE LA PRIMERA GUERRA MUNDIAL

\begin{tabular}{|c|c|c|c|}
\hline \multicolumn{2}{|c|}{$\begin{array}{c}\text { CASA DE AMERICA } \\
\text { Asociación } \\
\text { Internacional lberoamericana }\end{array}$} & \multicolumn{2}{|c|}{ Repertorio iconográfico de Delegados en América } \\
\hline \multicolumn{2}{|c|}{ República del Toraganau } & \multicolumn{2}{|c|}{ Distrito: Eosa la Opepibsira } \\
\hline \multicolumn{2}{|c|}{ Ciudad de residencia Prsmucróns } & \multicolumn{2}{|c|}{ 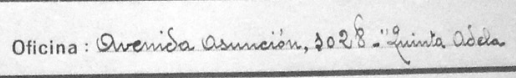 } \\
\hline \multicolumn{4}{|c|}{ Nombre : Oamilo Peres y Perer } \\
\hline \multicolumn{2}{|c|}{ Fecha del nombramiento: $2 \mathrm{~d}$ Chril 1914} & 1912, Fecha de su ace & ación: 16 frum de 1914 \\
\hline 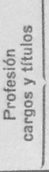 & 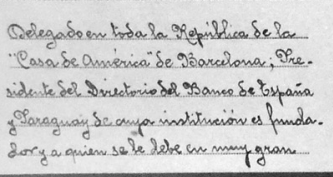 & 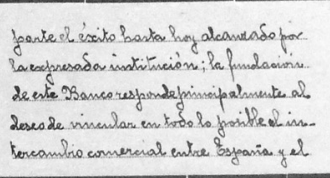 & 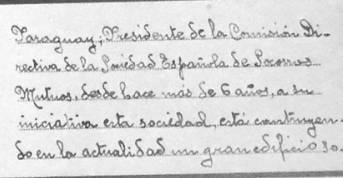 \\
\hline
\end{tabular}

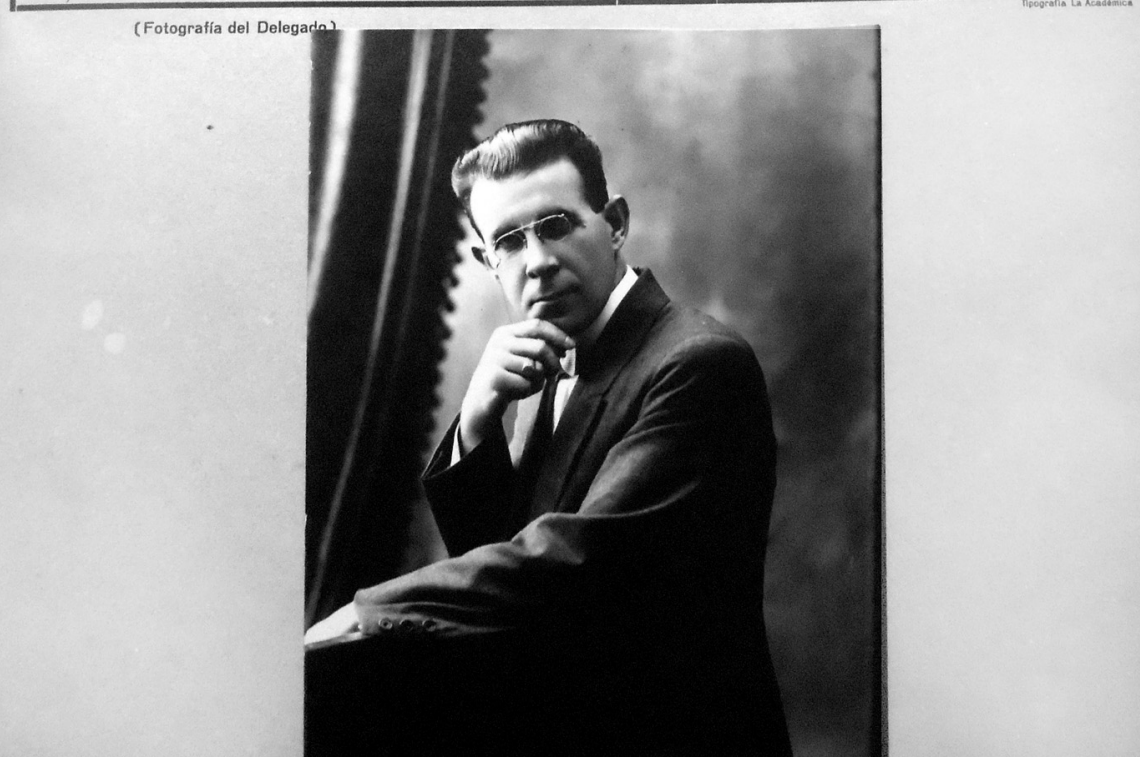

Camilo Pérez y Pérez. Delegado de la Casa de América, Asociación Internacional Iberoamericana, en la República del Paraguay. Barcelona, 1914. CA-AG, 3, Repertorio iconográfico de delegados en América. 
hizo llegar a «Tipografía La Académica» de Barcelona. Los responsables de la Casa de América incluyeron la biografía de este nuevo delegado, afirmando su libre disposición como interlocutor entre su patria y el país receptor y su condición de emigrante:

Es queridísimo por sus connacionales y hombres de toda clase de significación social, tanto en la política como en la banca y comercio. No se da tregua por todo lo que significa engrandecer su patria, su comercio y sus hombres. Debido a su gran bondad, no es hombre de fortuna, pero por sobre ésta, tiene otra más importante a su manera, que es la de hacer bien a todos los que puede, y de servir y enaltecer a su patria en todos los actos. Todos los cargos alcanzados son fruto exclusivo del reconocimiento de su comportamiento durante muchos años de trabajo, de su buena conducta y comportamiento en todos sus actos. Salió de España para América a los 17 años el día 7 de mayo 1895, no contando con más protección que el producto honrado de su fecundo y constante trabajo. ${ }^{37}$

El primer informe que Pérez envió a la Casa de América fue reproducido en la revista Mercurio. En ese texto se centró en la difícil situación paraguaya en el marco de la conflagración europea. Según él, el estallido de la guerra atentaba contra el futuro del país, ya que el gobierno todavía gestionaba en Europa y en los Estados Unidos de América un importante empréstito de 1.250.000 libras, que se había tramitado después de la guerra de la Triple Alianza. Este contexto histórico, según él, podía favorecer a los miembros de la Casa, pero a cambio de concesiones arancelarias y exclusivas que fuesen favorables a la importación de los productos paraguayos en España.

A este primer informe le siguieron innumerables esquelas y notas sobre la exportación de tabaco y de cueros vacunos, tanto secos como salados. En esos textos Pérez propuso que la tabacalera española dejase atrás su dependencia respecto a Hamburgo, y que reforzase las relaciones con Paraguay ya que este país facilitaba un comercio de tabaco a más bajo precio. Según él, España podía evitar así el recargo de comisiones de los intermediarios, y frenaría la ganancia que estos últimos imponían en la transacción. Desde Asunción le recordó a Vehils que el acercamiento comercial era consecuencia lógica del intercambio, y que por ello España estaba obligada a aprovechar las especiales circunstancias del momento. Si el gobierno paraguayo se encontraba en esos momentos negociando el empréstito otorgado por Europa y por los Estados Unidos de América, la Casa podía

37 CA-AG, 3, Repertorio iconográfico de delegados en América. 
apoyar una nueva contratación en España, a cambio de ciertas concesiones arancelarias y exclusivas que fuesen favorables a la importación de sus productos en la República del Paraguay. Esta sugerencia se sumó a otra información: por telégrafo se había anunciado que el Banco de España había acordado establecer sucursales en Buenos Aires, Estados Unidos y Río de Janeiro. No estaba claro, según él, que esta noticia fuese cierta, pero sí le pareció oportuno afirmar que dicho banco podía establecer una agencia en Asunción para fomentar así, y en un grado superlativo, las transacciones con España. La guerra europea, afirmaba, había generado un pánico comercial extraordinario entre los miembros del gobierno, los cuales se habían visto obligados a dictar medidas urgentes. En particular, decretaron quince días feriados, una moratoria general de 140 días de las operaciones en oro sellado, y la emisión de 25 millones de pesos en papel moneda a través de la ley sancionada por las dos Cámaras Legislativas. Esta medida estableció que sus valores fuesen reembolsables con un año de plazo, evitando así que los bancos suspendiesen sus pagos. Según sus palabras, el mencionado cambio había subido del $2.000 \%$ al $3.000 \%$ en virtud de la paralización de los artículos principales de exportación, como podían ser cueros vacunos, tanto secos como salados, junto al tabaco y el tanino procedente del árbol de quebracho colorado de la zona chaqueña. Los mercados principales de estos productos eran Alemania, Inglaterra y Francia, países afectados por la guerra mundial, y por ello el gobierno paraguayo había optado por volcar su producción a los Estados Unidos de América.

Desde Madrid, Vehils le contestó que era prioritario favorecer la relación entre Cataluña y los empresarios establecidos en Paraguay, y entre estos últimos los que mostrasen interés en exportar cuero, tabaco y madera a Europa. En el primer caso, los cueros debían ser enviados en consignación a la «F. Malagarrida Fabra Sen Co.», empresa ubicada en la calle Ancha n. ${ }^{\circ} 29$, de la ciudad condal, tarea acompañada con datos concretos sobre cantidad, clase, peso del cuero, y el precio al que llegaba el transporte entre las capitales de Argentina y Uruguay: Buenos Aires y Montevideo. El cálculo siempre fue en francos y por $50 \mathrm{~kg}$ de peso, cumpliendo así con la condición impuesta por la «Compañía Trasatlántica» del marqués de Comillas. ${ }^{38}$

Pérez decidió entonces enviar a Vehils la información sobre las haciendas que eran de propiedad de la «Pérez y Sanjurjo S.A.», donde las

38 CA-AG, 12.3, Vehils (Barcelona) a Pérez (Asunción), 5 de octubre de 1914; 4 de marzo de 1915 . 
mujeres paraguayas trabajaban en la recogida de semillas, el recurso natural que podía servir para el fomento mercantil entre Paraguay y España. Siguiendo la idea que una década antes había expresado el catalán Jorge Bach en la revista Mercurio, Pérez sostuvo en una de sus cartas que la población masculina paraguaya se había reducido por efecto de la guerra de la Triple Alianza, frente a un mundo feminizado que se había visto obligado a trabajar para cubrir las necesidades de las familias paraguayas.

En abril de 1915 Pérez le hizo llegar a Vehils su cuarto informe trimestral en el que se refirió a la producción paraguaya y a la ineludible presencia de políticos y de empresarios estadounidenses que estaban desalojando a sus pares españoles, y que pretendían reformar el sistema financiero y bancario. Según él, mientras los primeros conferenciaban con los representantes del gobierno para obtener concesiones y novedosas leyes que pudiesen favorecer la importación de sus productos y la inversión de sus capitales, los segundos organizaban reuniones en los centros comerciales paraguayos para propagar la bondad de sus mercaderías y el valor de las transacciones de sus sucursales bancarias. De acuerdo con Pérez, el mensaje que circulaba en Paraguay no era otro que la promesa estadounidense de regularizar el intercambio y de fijar de manera cristalizada el «crédito americano», haciendo alusión al crédito otorgado por Estados Unidos de América. ${ }^{39}$

Para reforzar la presencia española en Paraguay, Pérez decidió confesar que la ciudad de Asunción había recibido en esos días la visita del delegado de la «Misión Baudin», el organismo oficial del gobierno francés. Este delegado se encontraba reunido con el presidente paraguayo Eduardo Schaerer Vera y Aragón, y con los miembros de la Cámara de Comercio, con la intención de instalar un banco y facilitar el recorrido a las compañías de navegación francesas para que se acercasen al puerto de Asunción al menos una vez por mes. ${ }^{40}$

Ante esta situación, Pérez señaló en uno de sus informes que la única solución era instalar un banco español que pudiese proteger los intereses relacionados con la venta de mercaderías españolas que ofrecían los comerciantes en el Paraguay. Para ello hizo llegar a Vehils los datos oficiales de las decisiones tomadas por las Cámaras Legislativas paraguayas, como por ejemplo la creación de una Oficina de Cambios a cargo del senador

39 CA-AG, 12.2, Pérez (Asunción) a Vehils (Barcelona), 26 de mayo de 1915.

40 Ibidem, 30 de junio de 1915. 
Gerónimo Zubizarreta, la designación de Evaristo Acosta como director del Banco Agrícola del Paraguay, y de Luis Peraso como síndico del Banco de la República, y la modificación de la Ley de Moratorias. En contrapartida, Pérez divulgó en Asunción uno de los textos publicados por la revista barcelonesa Mercurio con el título «Política económica de Inglaterra ante el actual conflicto», y que había sido elaborado por Joaquín Sánchez de Toca, por entonces presidente del Senado de España y miembro de la Real Academia de Jurisprudencia y Legislación. ${ }^{41}$

A inicios de 1916, Pérez abrió las puertas del Banco de España y Paraguay a través de un capital autorizado y de una moneda legal que llegaba a 20 millones de pesos paraguayos. Justificó esta decisión diciendo que el directorio estaba compuesto por capitalistas españoles, y que su objetivo era fomentar de manera patriótica el intercambio comercial y bancario entre ambos países para contrarrestar la presión ejercida por los gobiernos europeos para «aniquilar la influencia de nuestra expansión comercial en estas Repúblicas Hispano-Americanas». ${ }^{42}$

Fue en ese año de 1916 cuando Pérez le comunicó a Ramón Méndez de Cardona y a Rafael Vehils que el gobierno paraguayo había otorgado el derecho de reconstruir el puerto de Asunción a la compañía estadounidense «MacArthur \& Cía.». Desde hacía un tiempo, el puertorriqueño Méndez de Cardona había asumido el cargo de presidente de la Casa de América de Barcelona. Hablamos de un hacendado que durante la dominación española llegó a la categoría de jefe de administración de la Hacienda Pública de Puerto Rico. Afiliado al partido autonomista, representó en las Cortes españolas al distrito de Utuado. Antes del establecimiento del gobierno civil en Puerto Rico, formó parte del Consejo Consultivo creado durante el gobierno militar del general David, en el cual figuraban nueve vocales escogidos entre las personalidades de más importancia en la isla de Puerto Rico. Después del cambio de soberanía, representó a la circunscripción de Humacaco, gracias a su afiliación al Partido Unionista, y fue designado en diversas oportunidades como presidente de la Comisión de Hacienda de las Cámaras de Diputados y Senadores de Puerto Rico. También fue concejal del Ayuntamiento de San Juan, presidente del Comité Provincial del distrito, y en 1912 fue nombrado representante de Puerto Rico en el centenario de las Cortes de Cádiz. Establecido en ese mismo año en la ciudad de

41 CA-AG, 12.3, Vehils (Barcelona) a Pérez (Asunción), 3 de agosto de 1915.

42 CA-AG, 12.2, Pérez (Asunción) a Vehils (Barcelona), 1 de abril de 1916. 
Barcelona, aceptó presidir la Casa de América «para consagrarse a la meritoria labor de relación e intimidad iberoamericana que constituye el objetivo de esa corporación». En ese año, el paraguayo Manuel Franco (1871-1919) había asumido la presidencia del país acompañado por el vicepresidente José P. Montero, junto a los siguientes ministros: Manuel Gondra, Luis A. Riart, Ernesto Velázquez, Eligio Ayala y Félix Paiva. Y la República Argentina había impuesto la firma del «Tratado de Comercio» con Paraguay ${ }^{43}$ demostrando así el poderío que gozaba en el espacio rioplatense. ${ }^{44}$

Vehils se hizo cargo de estos informes, pero reiteró que era imposible ejecutar los proyectos en medio de un conflicto bélico, aunque sí imprescindible el hecho de organizar proyectos productivos y comerciales que se pudiesen llevar adelante desde el momento en que se firmasen los tratados de paz. Este fue el motivo por el cual la Casa decidió organizar en la ciudad condal la Exposición de Industrias Eléctricas y General Española. ${ }^{45}$ Ahora bien: el comité organizador decidió incluir una sección especial dedicada a la acción de los españoles residentes en América y en las Islas Filipinas, las antiguas colonias monárquicas españolas, y para ello diseñaron la Sección de Acción Española en Ultramar.

En el caso paraguayo, los responsables de la Casa optaron por incorporar al Centro Español como «institución protectora», con la condición de que abonara anualmente una cuota de 100 pesetas. ${ }^{46}$ Esta asociación estaba domiciliada en la calle Palmas n. ${ }^{\circ} 175$ de la ciudad de Asunción, y su objetivo de origen fue simplemente recreativo. El año de su fundación fue 1898, y por entonces el número de socios españoles llegaba solo a 150 varones. Los no españoles sumaban un total de 420 , mientras que los socios honorarios llegaban a 20. Esta entidad era presidida por Enrique Prous, y Leonardo Castro actuaba como vicepresidente. ${ }^{47}$

Por esas fechas Vehils le solicitó a Pérez que consiguiese que un buen número de organismos españoles se inscribiesen en la Casa, ya que era conveniente «conseguir ingresen en esta asociación al mayor número posible de colectividades españolas». ${ }^{48}$ Para ello contactaron también con el

\footnotetext{
43 Ibidem, 30 de junio de 1916 y 30 de setiembre de 1916.

44 Figallo Lascano, 2014.

45 CA-AG, 12.3, Vehils (Barcelona) a Pérez (Asunción), 16 de noviembre de 1916.

46 CA-AG, 12.3, Casa de América (Barcelona) a Pérez (Asunción), 28 de febrero de 1917.

47 CA-AG, 12.2, Pérez (Asunción) a Vehils (Barcelona), 10 de agosto de 1917.

48 CA-AG, 12.3, Vehils (Barcelona) a Pérez (Asunción), 28 de febrero de 1917.
} 
Centre Català, la entidad que había sido inaugurada el 25 de noviembre de 1914 en un edificio alquilado de la calle Ayolas, esquina Buenos Aires, de Asunción. La tarea del Centre Català era organizar actos sociales, exhibiciones artísticas y culturales, y muestras musicales, disponiendo para ello las secciones «Orfeón» y «Arte Escénico» en las que, según los datos señalados por el delegado Pérez, participaron unos 278 socios de origen catalán..$^{49}$

Desde el año 1911 Camilo Pérez ejercía la presidencia de la Sociedad Española de Socorros Mutuos de Asunción, entidad que había sido inaugurada el 9 de marzo de 1873 con el objetivo de garantizar la beneficencia, el socorro entre los españoles menesterosos y el intercambio comercial entre España y Paraguay. En el año 1917 Pérez era acompañado por su secretario D. Sandoval, y por los vocales Enrique Prous, Pascual Ordiñana, Antonio Gastón Brun, Miguel Rueda, Salvador Espelt, Dionisio Guillen, Antonio Casariego, Agustín Lledó, Juan J. Bilbao, Blas Telechea y Antonio Sanjurjo, su colega en la «Pérez y Sanjurjo S.A.».

La Sociedad Española de Socorros Mutuos contaba con unos 600 socios, y su tarea seguía siendo socorrer exclusivamente a sus asociados españoles en caso de enfermedad o fallecimiento. Entre sus fines también aparece la celebración de las «glorias de España», y el principio de estrechar la unión y la fraternidad entre todos los españoles residentes en Paraguay, incluyendo a sus descendientes. Pérez hizo llegar a Barcelona la nota de esta asociación que iba dirigida a sus «compatriotas españoles». En ella, la patria aparece como una nación que halaga la paz y la concordia frente al resto de naciones europeas volcadas a la destrucción de la civilización. Los españoles de América no debían permanecer indiferentes ante esos momentos decisivos que orientarían el porvenir. Debían estar preparados para colaborar con los países que llevaban su sangre, su idioma y sus costumbres: la colonia española en Paraguay podía formar un núcleo idóneo para dignificar el nombre de España, servir de lazo con la antigua metrópoli, atraer su literatura y sus productos industriales y comerciales, y gestar la unión intelectual y material para conservar el carácter de «buenos españoles y buenos amigos de esta noble tierra paraguaya».50

49 CA-AG, 12.2, Centre Català (Asunción) a Pérez (Asunción), 9 de julio de 1917.

50 CA-AG, 12.2, Sociedad Española de Socorros Mutuos de Asunción, Paraguay, 28 de mayo de 1918. 


\section{El Banco de España y Paraguay ante la guerra}

Siguiendo con la reglamentación establecida para los delegados de la Casa de América, Pérez hizo llegar a la ciudad condal los informes trimestrales en cuyas páginas abordó las huelgas parciales y generales que se estaban produciendo en todos los gremios paraguayos, junto a la modificación de la ley electoral del voto secreto al establecer la inscripción obligatoria a todos los ciudadanos paraguayos que supieran leer y escribir. A esto se sumó el hecho de que Camilo Pérez asumió de forma temporal el cargo de cónsul de España en Paraguay. Pocos meses después, en setiembre de 1917, Luis Rubio Amoedo, quien se había desempeñado hasta entonces como cónsul de Cap-Town (Ciudad del Cabo), sustituyó a Pérez en calidad de cónsul general. ${ }^{51}$

Como vemos, era hora de enfrentar los efectos de la guerra a través de la organización de vínculos internacionales entre España y Paraguay. Por entonces el nuevo presidente de la Casa de América era Federico Rahola Trèmols, quien junto a Vehils decidió remitir a Pérez una nota general sobre la posible participación de los españoles establecidos en la tierra hispanoamericana durante la Exposición de Industrias Eléctricas y General Española, que se llevaría a cabo en el año 1919. La idea era organizar también una pequeña Exposición Mercológica Americana, en la que fuese posible incluir datos científicos y literarios, como también muestras de productos paraguayos agrícolas, mineros y manufactureros, junto a los dedicados a la ganadería - como por ejemplo la «Liebig Extract of Meat Company»—, ${ }^{52}$ es decir, recursos que hasta entonces no habían sido valorados en las transacciones comerciales con España. ${ }^{53}$

En el primer caso, referido a datos científicos, Pérez avisó que no existía una ley relativa a la propiedad literaria en virtud del rechazo, por tiempo indefinido, que había hecho el Senado frente a las propuestas presentadas por la Cámara de Diputados. A esto se sumaba el hecho de que el centro cultural «Gimnasia y Esgrima» había recibido en esos días la visita del ministro plenipotenciario de la República Argentina, José María Cantilo, quien ofreció un coloquio público sobre el peso de la literatura argentina, frente a

51 CA-AG, 12.2, Pérez (Asunción) a Vehils (Barcelona), 4 de abril de 1917; 30 de junio de 1917; 2 de julio de 1917 y 30 de setiembre de 1917.

52 Caballero Vargas, 2009.

53 CA-AG, 12.3, Vehils (Barcelona) a Pérez (Asunción), 1 de marzo de 1917; 20 de mayo de 1917; 30 de mayo de 1917; 22 de agosto de 1917; 27 de setiembre de 1917 y 12 de noviembre de 1917. 
las conferencias que hicieron las escritoras españolas Belén de Sárraga y Concepción Gimeno de Flaquer en el Instituto Paraguayo establecido en Asunción. Pérez consideraba imprescindible recibir a personalidades españolas que pudiesen garantizar la «alta cultura» y las «grandezas y virtudes de la patria lejana», ya que el dominio argentino era demasiado grande frente al que podía diseñar la República del Paraguay. Como él mismo señalara, el posible conflicto bélico desatado entre Bolivia y Paraguay por las tierras chaqueñas,${ }^{54}$ seguía siendo un problema irresoluble.

En el segundo caso, que hace mención a las muestras de productos paraguayos, las cartas se refirieron a la venta del vapor nacional llamado «Constitución» para invertir ese dinero en la deuda interna y el pago de las obligaciones atrasadas, la construcción de cuarteles, la culminación de la construcción de los muelles de Concepción y Villeta, el socorro a los pobres y el reparto de semillas a los agricultores, la compra de un local para construir la cárcel correccional de mujeres, la compostura de caminos así como recursos y útiles escolares. En los hechos, el gobierno paraguayo había tomado la decisión de ejecutar la Ley del Servicio Militar Obligatorio (decreto N. . 6878). Según Pérez, ese año de 1917 constituía un momento especial para el Paraguay, ya que la poderosa firma norteamericana «Swift» había adquirido la «Compañía Paraguaya de Frigorífico y Carnes Conservadas»..$^{55}$

Ahora bien: el comité organizador de la Exposición de Industrias Eléctricas y General Española le pidió a Pérez una copia del mensaje leído por el presidente paraguayo en el Congreso de la República del Paraguay, los datos básicos sobre la tenería, y la «Guía del Paraguay» que contenía la ley de marcas de fábricas y patentes. En ese año 1918, Vehils asumió como diputado de las Cortes Generales de España y director de la novedosa Oficina Regionalista de Madrid, cargos que le había otorgado, precisamente, Francesc Cambó. ${ }^{56} \mathrm{Y}$ fue el propio Cambó, ${ }^{57}$ convertido entonces en un destacado líder político además de responsable de la Casa de América de Barcelona, quien le comunicó a Vehils la necesidad de contar con la ayuda de Camilo Pérez para la ejecución de los proyectos que servirían para acrecentar el crédito. Pérez, por su parte, decidió reproducir en el diario de

54 Scavone Yegros, 2004.

55 CA-AG, 12.2, Pérez (Asunción) a Vehils (Barcelona), 10 de agosto de 1917; 30 de setiembre de 1917; 31 de diciembre de 1917.

56 Ibidem, 22 de julio de 1918; 30 de setiembre de 1918.

57 Riquer i Permanyer, 2005, 2007. 
Asunción llamado La Tribuna, el trabajo que Vehils tituló «La Unión Interparlamentaria Hispano-Americana», junto a las notas elaboradas por Álvaro de Figueroa Torres, el conde de Romanones, que ejerció la presidencia del Consejo de Ministros de Estado en tres ocasiones, siendo su último periodo de acción política en los años 1918 y $1919 . .^{58}$

En uno de sus informes trimestrales, Pérez incluyó la biografía de Cecilio Báez, quien fue nombrado ministro plenipotenciario y extraordinario del Paraguay ante los gobiernos de Inglaterra, Francia y España. Para el delegado de la Casa, Báez era más que un eminente publicista. Se trataba de un paraguayo que había ocupado el alto cargo de presidente de la República del Paraguay, además de asumir los cargos de ministro de Relaciones Exteriores en diversas oportunidades, el de miembro de la Alta Corte de Justicia, rector y catedrático de la Universidad Nacional de Asunción, así como el de senador y diputado del Congreso paraguayo. Por ello Pérez tenía grandes esperanzas depositadas en el posible encuentro de Báez con Antonio Maura y Montaner, el presidente del Consejo de Ministros de España (1901-1904, 1907-1909, 1918, 1919, 1921-1922). El delegado señaló en su carta que la persona más importante de ese posible encuentro entre Báez y Maura era el catalán Francesc Cambó, quien para él representaba «un verdadero resurgimiento nacional», ${ }^{59}$ en virtud del apoyo incondicional que aportaría el nacimiento del partido clave de la España de inicios del siglo XX: la «Lliga Regionalista» de Cataluña. ${ }^{60}$

En el año 1918, el presidente Camilo Pérez, junto al gerente Antonio Casariego, inauguró el local propio del Banco España y Paraguay mediante un acto público al que asistieron el ministro de Hacienda Eusebio Ayala, el subsecretario de Relaciones Exteriores, el intendente municipal, el jefe de policía de la capital, y personalidades de la banca, del comercio y de las industrias establecidas en Paraguay, entre ellos Faustino Villabrille, el gerente del Banco de España y América de Buenos Aires. El abogado español Matías Alonso Criado ofreció un discurso a pedido de la concurrencia, y reafirmó el acercamiento entre Paraguay y la «madre patria». Junto a Matías Alonso, el concejal Enrique Prous, también español, reconoció que ese Banco de España y Paraguay había sido fundado «en momentos

58 CA-AG, 12.3, Vehils (Barcelona) a Pérez (Asunción), 15, 20 y 27 de enero de 1918; 31 de abril de 1918; 5 de junio de 1918; 29 de agosto de 1918; 4 de setiembre de 1918; 20 de noviembre de 1918; 4 de diciembre de 1918.

59 CA-AG, 12.2, Pérez (Asunción) a Vehils (Barcelona), 4 de abril de 1918.

60 Riquer i Permanyer, 2008. 


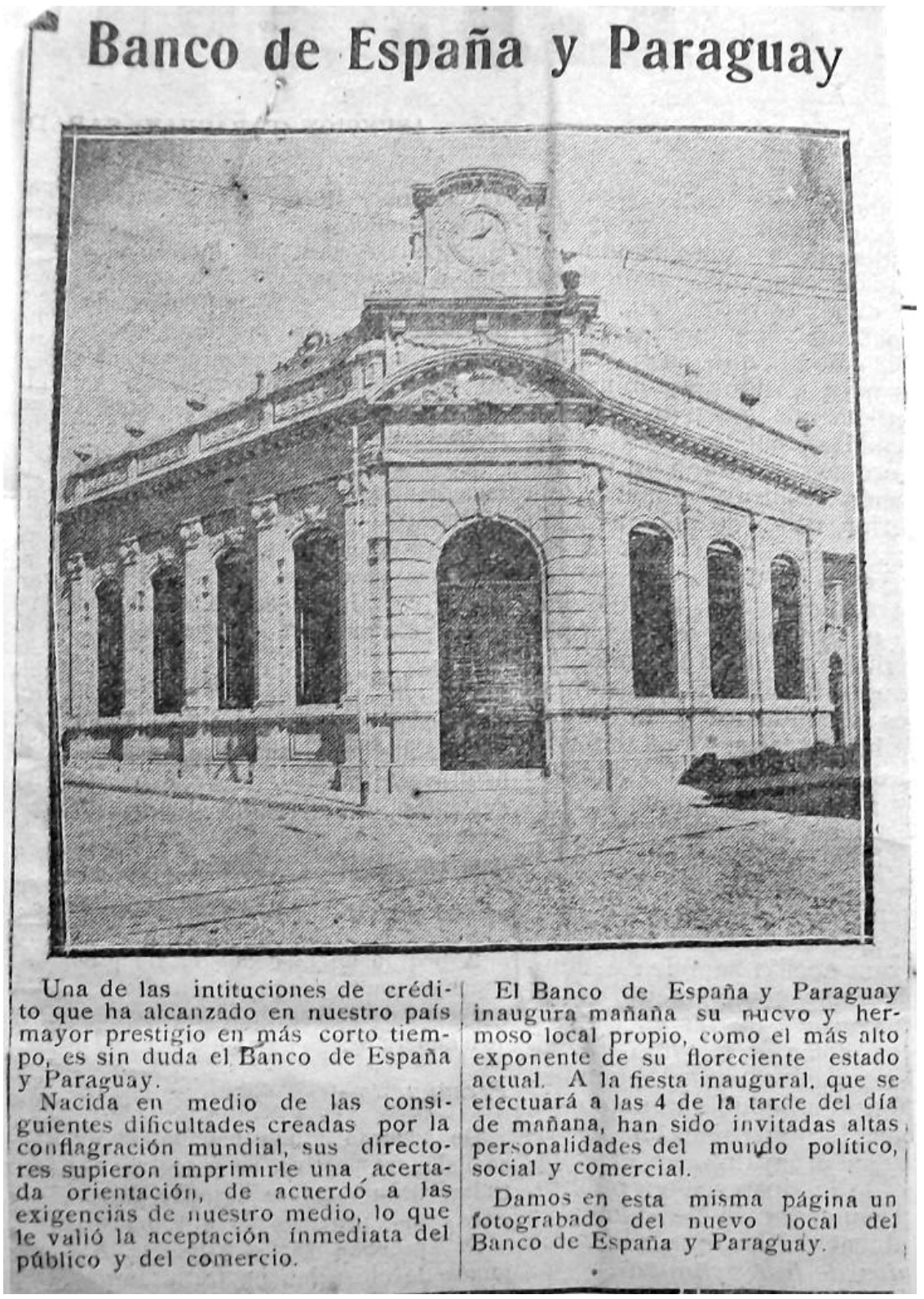

Banco de España y Paraguay. Página enviada por su director, Camilo Pérez y Pérez, Asunción del Paraguay, 1918. CA-AG, 12.2 (entrada). 
críticos producidos por la conflagración europea». ${ }^{61}$ Gracias a esa entidad bancaria, desde 1914 se habían formado las primeras empresas frigoríficas, habían sido impulsadas algunas industrias y empresas comerciales, y se habían facilitado las operaciones de orden público y privado. Por todo ello habían conseguido un local propio. Reproducimos aquí la página de un periódico paraguayo que Pérez hizo llegar a Barcelona en el año 1918, haciendo referencia a su original banco español y paraguayo.

Desde ese año de 1918 Vehils se encargó de solicitarle que cobrara la cuota anual al Centro Español de Asunción por su calidad de socio de la Casa de América barcelonesa, al tiempo que reconoció las dificultades que ofrecían las leyes españolas al intentar introducir los recursos de origen paraguayo. Las experiencias del reino ante las acciones llevadas adelante por el Banco Español del Río de la Plata, el Banco Central Mexicano y el Banco Español de Cuba, tampoco favorecían un posible apoyo al Banco de España y Paraguay con sede en Asunción. Lo único que podían organizar era una especie de exposición de muestras. ${ }^{62}$

Ante esta situación, Pérez se refirió a la escasa colaboración gubernamental española que había dejado casi a solas a los propios españoles establecidos en Paraguay que trabajaban sin cesar por el prestigio patrio. Según él, en esos años de conflicto bélico internacional se había infiltrado el capital estadounidense, de forma franca y decidida, para avalar la explotación industrial que era ejecutada por los frigoríficos que aprovechaban los campos y la ganadería paraguaya, y cuyos productos resultantes llegaban a los mercados europeos y estadounidenses. Las industrias estadounidenses ampliarían su acción mediante la intervención en los negocios, y el control económico, comercial, monetario y financiero del país, tarea a la que se sumaban los capitales argentinos. ${ }^{63}$ De ahí la conclusión de Pérez de que era urgente contrarrestar «la influencia de otros países que, apoyados eficazmente por su comercio y gobiernos, no escatiman medios para triunfar sobre el nuestro». Pérez sostuvo también que, después de la guerra, le llegaría el turno a la cruenta batalla comercial en la que la victoria quedaría en manos del país más preparado. Por ello en su carta enviada a Rafael Vehils decidió concluir su escrito con la siguiente frase: «¿lo estamos nosotros?». ${ }^{64}$

61 CA-AG, 12.2, Pérez (Asunción) a Vehils (Barcelona), 1 de setiembre de 1918.

62 CA-AG, 12.3, Vehils (Barcelona) a Pérez (Asunción), 27 de abril de 1918; 30 de diciembre de 1918; 11 de enero de 1919.

63 Campos Doria, 2010.

64 CA-AG, 12.2, Pérez (Asunción) a Vehils (Barcelona), 30 de setiembre de 1918. 
A finales de ese año 1918, Pérez afirmó que, frente al resto de los países europeos y de los propios Estados Unidos de América, su país de origen, España, había cometido el gran error de otorgar escasa relevancia a la acción diplomática en sus antiguos territorios coloniales americanos. Algunos países de Europa, como también los Estados Unidos, rivalizaban con inteligencia y perseverancia, gracias a su proyecto de captar la simpatía de la población de la América hispana. En general, lo hacían a través de ingentes sumas de dinero, y mediante recepciones y fiestas sociales. Por ello, ese 31 de diciembre de 1918 Pérez le escribió a Vehils afirmando que se mencionaba con frecuencia que al finalizar la guerra Estados Unidos se apoderaría del mercado internacional. Para el caso paraguayo, llamativamente, al gobierno estadounidense se sumarían Inglaterra, Francia, Argentina, Brasil y Uruguay. Según él, solo una acción conjunta, inteligente y rápida podía contrarrestar esta presión que afectaba a los españoles migrantes que estaban dispuestos a «cooperar para el desarrollo de las industrias patrias». ${ }^{65}$

Al año siguiente, en 1919, el delegado Pérez aceptó enviar a la ciudad condal los productos paraguayos más importantes para la exposición diseñada por Rafael Vehils, pero con la condición de que la Casa de Barcelona cubriese los gastos del flete con las ventas de los productos. También envió tres informes trimestrales en los que repitió la intensificación de la presencia de Inglaterra y de los Estados Unidos de América con el fin de apoderarse de este mercado. Según él, durante el mes de octubre de 1919 el Banco de Londres y Río de la Plata resolvió establecer una sucursal en Asunción. También el Banco Agrícola del Paraguay que había iniciado una importante propaganda para intensificar el cultivo del algodón y cumplir con la exigencia manifestada por el mercado estadounidense. ${ }^{66}$

El 12 de octubre de 1919 fue inaugurado el local social de la Sociedad Española de Socorros Mutuos de la colonia y pueblo paraguayo. Días después se presentó ante la Legación de España en Paraguay el agregado militar, comandante E. Montó, quien tomó contacto con sus colegas paraguayos, en particular el ministro de Guerra y altos jefes del Ejército, la oficialidad y alumnos de la Escuela Militar que era presidida por el director del establecimiento. El acto fue organizado por las Sociedades

65 Ibidem, 31 de diciembre de 1918.

66 Ibidem, 20 de marzo de 1919; 23 de julio de 1919 y 30 de setiembre de 1919. 
Españolas, las cuales fueron presididas por el encargado de negocios de España en Paraguay. Finalmente, el propio ministro de Hacienda y ex ministro de Relaciones Exteriores, Eusebio Ayala, había decidido viajar a los Estados Unidos de América para representar al Gobierno del Paraguay en el Congreso Financiero Panamericano. Eusebio Ayala fue acompañado por R. Croskey y por Enrique Bordenabe. ${ }^{67}$

Camilo Pérez decidió renunciar a su condición de delegado, ya que si bien reconocía que su intención era curarse de una enfermedad en los riñones, agregó que solo tenía 42 años de edad, que ya había trabajado demasiado y que era el momento de dedicarse a su propia esposa, a sus tres hijos y a sus amigos. Pero en la carta agregó de manera indirecta que también había tomado consciencia de que los Estados Unidos de América se aprestaban a la dominación de los mercados americanos, todas noticias que llegaron a Vehils. ${ }^{68}$ Este último, director de la Casa de América, por su parte, decidió pedir a la «Compañía Trasatlántica», al marqués de Comillas y al conde de Romanones, que aceptasen el nombramiento de la «Pérez y Sanjurjo S.A.» como representante y agente en Asunción. No había duda alguna de que había que hacer algo más que publicitar los informes de Pérez en las páginas de Mercurio, o celebrar sus contactos con la Federación de Centros Españoles en América. Por ello Vehils le rogó que ofreciese el nombre de un posible sustituto. ${ }^{69}$

Ante esto, la decisión de Pérez fue otra: hizo llegar a Barcelona los datos de la huelga marítima que incomunicaba al Paraguay respecto a sus países limítrofes, y el viaje de Manuel Gondra desde Washington para acceder a la segunda presidencia del país. Según él, la transformación política era acompañada por un excesivo costo de todos los artículos de producción extranjera, la subida del cambio y la desvalorización de los productos paraguayos en los mercados europeos. Hasta finales de 1920, este desconcertado delegado no pudo hacer llegar ni siquiera una carta a la ciudad condal. Según sus palabras, la mala situación económica del Paraguay - consecuencia de la desvalorización y del estancamiento general de todos sus productos - le había forzado a cerrar las puertas del «Banco de España y Paraguay». Como él mismo señalara, ocurrió lo

67 Ibidem, 20 de diciembre de 1919.

68 CA-AG, 12.3, Vehils (Barcelona) a Pérez (Asunción), 2 y 9 de enero de 1919; 13 y 15 de febrero de 1919; 9 de abril de 1919; 6 y 10 de junio de 1919.

69 Ibidem, 23 de agosto de 1919; 5 de julio de 1920; 13 de agosto de 1920. 
mismo con el «Banco Mercantil del Paraguay» y con la casa de banca de «A. Perasso \& Cía». ${ }^{70}$

En ese momento existían en Barcelona unos 30 bancos, y Vehils acudió a los de «Urquijo Catalán», «Hispanocolonial» y a la «Banca Arnús». En todos ellos le confirmaron que era casi imposible mantener la relación con Paraguay. El 25 de mayo de 1921 le escribió a Pérez lo siguiente: «como Ud. ya sabe, la situación es la misma en mayor o menor escala en casi todos los países del globo». ${ }^{11}$ Por ello, el último informe trimestral que escribió Pérez el 4 de abril de 1921 hace referencia a la desvalorización de casi todos los productos naturales paraguayos que eran aptos para la exportación. Si bien el propio gobierno había hecho muy poco para remediar el estado de completa descomposición comercial del país, también existían otras razones, en particular las dificultades financieras que sufrían la mayor parte de los mercados europeos y americanos, además de los propios bancos del país receptor, sumado al escaso interés demostrado por su patria de origen para restablecer las relaciones internacionales con la República del Paraguay. ${ }^{72}$ Vehils solo pudo afirmar que lamentaba la situación anómala de ese país y que esperaba cierta normalización de su economía. Le agradeció el envío de algunos volúmenes del periódico paraguayo El Liberal, que contenían el texto escrito por Pérez titulado «Más sobre ibero-americanismo», como también el memorándum de los establecimientos productivos radicados en tierras paraguayas. Ante ello le contestó haciendo referencia a Eduardo Sanz y Escartín, el conde consorte de Lizárraga —en ese año 1921 nombrado ministro de Trabajo y gobernador del Banco de España-, quien confesó que todo dependía de las gestiones financieras con los bancos establecidos en Buenos Aires, ya que las circunstancias no eran favorables a la colocación de dinero fuera del reino. Todo dependía entonces de la reciente creación en Madrid del Crédito Territorial Español Trasatlántico. $^{73}$

A finales de ese año 1921, Pérez mencionó la convocatoria que hizo Felipe García Ontiveros, el encargado de negocios de España en Asunción, ${ }^{74}$ de organizar una comisión compuesta por presidentes de las

70 CA-AG, 12.2, Pérez (Asunción) a Vehils (Barcelona), 1 de julio de 1920; 28 de marzo de 1921.

71 CA-AG, 12.3, Vehils (Barcelona) a Pérez (Asunción), 5 y 14 de febrero de 1921.

72 CA-AG, 12.2, Pérez (Asunción) a Vehils (Barcelona), 4 de abril de 1921.

73 CA-AG, 12.3, Vehils (Barcelona) a Pérez (Asunción), 6 de julio de 1921; también véase 2 y 29 de agosto de 1921 .

74 López Sánchez, 2007, 91. 
sociedades españolas para enfrentar la «guerra en África». Eso sirvió para organizar un torneo de «foot-ball», y para recolectar fondos económicos a favor de la Cruz Roja Española de Melilla. Poco después, Vehils lo invitó a la III Feria Internacional de Muestras de Barcelona, que incluyó una sección sobre productos textiles americanos, pero repitió el pedido de que designase a otro representante que lo sustituyera en la labor de impulsar el proyecto hispano-paraguayo. ${ }^{75}$ Fue el fin de la vinculación formal entre Pérez, Paraguay y la Casa de América barcelonesa. La asociación catalana no encontró sustituto, y el tradicional delegado tampoco aportó nombre alguno.

\section{Conclusiones}

En 1914, iniciada la Primera Guerra Mundial, la Casa de América de Barcelona, entidad que desde 1911 buscaba reorganizar las relaciones hispano-americanas, nombró a Pérez y Pérez como delegado, con la tarea de modernizar y divulgar las relaciones peninsulares con Paraguay, y competir así con los países más involucrados en la participación económica: Argentina, Inglaterra, Francia y los Estados Unidos de América. Y las confrontaciones políticas internacionales que llevaron a los ejércitos boliviano y paraguayo a la destructiva guerra del Chaco, ${ }^{76}$ acompañaron la decisión de Camilo Pérez de abandonar su vinculación con entidades bancarias y empresas de su país de origen, y volcarse plenamente al sostenimiento de «La Paraguaya S.A. de Seguros», en la cual llegó a ser presidente en los años 1943-1946.

Como hemos analizado en este artículo, las acciones realizadas por los españoles migrantes en Paraguay tendieron a la consolidación de vínculos mercantiles y económicos en un amplio espectro de intereses: la creación del Banco de España y Paraguay en la ciudad de Asunción; la colaboración con la organización de exposiciones llevadas adelante en la ciudad condal para dar a conocer la producción de recursos naturales paraguayos; el intercambio comercial de productos tales como fibras, textiles, madera, extracto tánico...; la reciprocidad en el envío de libros científicos y litera-

75 CA-AG, 12.3, Vehils (Barcelona) a Pérez (Asunción), 1 de octubre de 1921; 11 de noviembre de 1921; 28 de marzo de 1922.

76 Scavone Yegros, 2010. 
rios entre España y Paraguay; la remesa de cartas y de informes oficiales y confidenciales relacionados con la estadística mercantil.

En todo este periodo en el cual se produjo la Primera Guerra Mundial, la revista Mercurio fue el instrumento privilegiado de comunicación y publicidad de las posibles relaciones entre España y Paraguay. Hemos querido rescatar las olvidadas figuras de Rafael Vehils i GrauBolívar y de Camilo Pérez y Pérez, protagonistas centrales de este proyecto americanista con el cual Cataluña buscó expandirse en la República del Paraguay, la antigua colonia hispana destruida por la guerra de la Triple Alianza, y rehecha a través de un modelo económico que en la época fue denominado moderno. El proyecto «pancatalanista» representó, en realidad, la ambición del expansionismo comercial, ${ }^{77}$ y utilizó la oportunidad ofrecida por el conflicto bélico del Paraguay, y en especial su neutralidad junto con España durante la Primera Guerra Mundial. Desde 1919, la relación con Estados Unidos de América trasmutó las posibilidades panamericanas de la Casa catalana, y forzó a renunciar a su representante en Paraguay. ${ }^{78}$

El periodo histórico que va de 1870 a 1930 transformó la sociedad y la economía del Paraguay, y en esos años en que Camilo Pérez intentó unirse al proyecto liderado por Vehils, se produjo una intensa lucha entre los partidos «colorado» y «liberal», ${ }^{79}$ situación que afectaría a la propia organización política de los inmigrantes de origen español establecidos en Asunción. Para los historiadores Ricardo Scavone Yegros y Liliana Brezzo, la postura que asumió Paraguay fue la de abstenerse ante la primera conflagración mundial en virtud de la decisión gubernamental de reconstruir al Paraguay después de la guerra de la Triple Alianza (1865-1870), el impulso otorgado a la difusión de empréstitos e inversiones internacionales, sumado al desarrollo de la controversia territorial suscitada con Bolivia por el control de Chaco Boreal. ${ }^{80}$

La guerra del Chaco formó parte de la expansión de los estudios petrolíferos del subsuelo chaqueño, que tuvieron lugar gracias a la empresa internacional «Standard Oil». ${ }^{81}$ El gran modelo americanista fue acompañado por otras interesantes experiencias de la época que proyectaron el

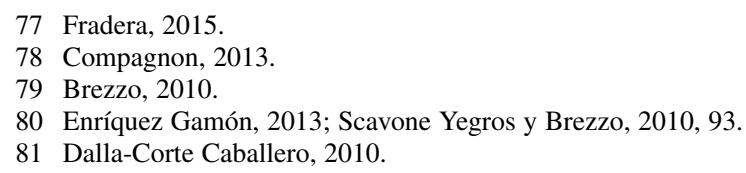


fortalecimiento cultural y lingüístico hacia las antiguas colonias. ${ }^{82}$ Experiencias que tuvieron un importante inicio en el marco de las celebraciones del centenario de las independencias de América, ${ }^{83} \mathrm{y}$ que fueron perdiendo fuerza desde el fin de la Primera Guerra Mundial - conflicto que incluyó con cierta originalidad al espacio latinoamericano— ${ }^{84}$ hasta el estallido de la Guerra Civil española. ${ }^{85}$

Recibido el 24 de junio de 2014 Aceptado el 8 de octubre de 2015

\section{Bibliografía}

Bach, Jorge: «Un viaje a la Asunción del Paraguay», Revista Comercial Iberoamericana Mercurio, II, 8, Barcelona, 4 de julio de 1902, 134-136.

Bernabéu Albert, Salvador: «El americanismo en el Centro de Estudios Históricos: Américo Castro y la creación de la revista Tierra Firme (1935-1937», en Dalla Corte, Gabriela, Lluís Vidal-Folch, Ariadna y Camps, Ferrán (coords.), De las Independencias al Bicentenario, Barcelona, Casa Amèrica Catalunya, 2006, 47-70.

Bernabéu Albert, Salvador: «Los americanistas y el pasado de América: tendencias e instituciones en vísperas de la Guerra Civil», Revista de Indias, 67, 239, Madrid, 2007, 251-282.

Brezzo, Liliana: «Reconstrucción, poder político y revoluciones (1870-1920)», en Telesca, Ignacio (coord.), Historia del Paraguay, Asunción, Taurus, 2010, 199-224.

Caballero Vargas, Guillermo: Liebig's en el Paraguay, Asunción, Editorial Intercontinental, 2009.

Cagiao Vila, Pilar (coord.): Cien anos da Biblioteca América (1904-2004), Santiago de Compostela, Universidade de Santiago de Compostela, 2004.

Cagiao Vila, Pilar: «Miradas españolas a las celebraciones de los centenarios de la independencia: así lo contó la prensa», en Cagiao Vila, Pilar y Portillo Valdés, J. M. (coords.), Entre imperio y naciones. Iberoamérica y el Caribe en torno a 1810, Santiago de Compostela, Servizo de Publicacións e Intercambio Científico, 2012, 459-484.

Campos Doria, Luis: Apuntes de historia económica del Paraguay, Asunción, Editorial Intercontinental, 2010.

82 Bernabéu Albert, 2007; Prado, 2008; Márquez Macías, 2012.

83 Cagiao Vila, 2004, 2012.

84 Dehne, 2014.

85 Bernabéu Albert, 2006. 
Cardús Huertas, Gualberto: Arado, pluma y espada, Barcelona, Domenech, 1911. Compagnon, Olivier: L'adieu à l'Europe. L'Amérique latine et la Grande Guerre, Paris, Fayard, Col. L'épreuve de l'histoire, 2013.

Dalla-Corte Caballero, Gabriela: La guerra del Chaco. Ciudadanía, Estado y Nación en el siglo XX. La crónica fotográfica de Carlos de Sanctis, Rosario, Prohistoria Ediciones, 2010 (reproducida por Intercontinental Ediciones, Asunción, 2010).

Dalla-Corte Caballero, Gabriela: Cultura y negocios: el americanismo catalán de la Revista Comercial Ibero-Americana Mercurio (Barcelona, 1901-1938), Barcelona, KM 13.774 Fundació Casa Amèrica Catalunya, 2012.

Dalla-Corte Caballero, Gabriela: El archivo documental del americanismo catalán. Una historia centenaria para la Casa de América (1909-1968), Barcelona, KM 13.774 Fundació Casa Amèrica Catalunya, 2013.

Dehne, Phillip: «How important was Latin America to the First World War?», Iberoamericana, XIV, 53, 2014, 151-164.

Enríquez Gamón, Efraín: Vientre de la tierra o la tragedia del Chaco, Asunción, Editorial Intercontinental, 2013.

Figallo Lascano, Beatriz: Argentina y España: entre la pasión y el escepticismo, Buenos Aires, Teseo, 2014.

Fradera, Josep María: La nación imperial (1750-1918), Barcelona, Edhasa, 2015.

López Sánchez, José María: «La Junta para ampliación de estudios y su proyección americanista: la institución cultural española en Buenos Aires», Revista de Indias, LXVII, 239, Madrid, 2007, 81-102.

Marcilhacy, David: Raza hispana. Hispanoamericanismo e imaginario nacional en la España de la Restauración, Madrid, CEPC, 2010.

Márquez Macías, Rosario (ed.): Huelva y América. Cien años de Americanismo. Revista «La Rábida» (1911-1933), Sevilla, Universidad Internacional de Andalucía, 2012.

Martínez Riaza, Ascensión: «La Compañía Trasatlántica en el Perú. Intereses diplomáticos y comerciales en la génesis y desarrollo de una empresa arriesgada (1899-1935)», Anuario de Estudios Americanos, LX-1, Sevilla, 2003, 157-182.

Morales Raya, Eva: «Migraciones invisibles: el caso de los catalanes en Paraguay a finales del siglo XIX y principios del XX», Naveg@merica. Revista electrónica de la Asociación Española de Americanistas [en línea], 8, 2012. http://revistas.um.es/navegamerica [Consultado: 15 de junio de 2012].

Naranjo Orovio, Consuelo: Las migraciones de España a Iberoamérica desde la Independencia, Madrid, CSIC, 2010.

Pla, Josefina: Viriato Díaz-Pérez: biografía, Palma de Mallorca, Luis Ripoll, 1993.

Prado, Gustavo H.: Rafael Altamira en América (1909-1910), historia e historiografía del proyecto americanista de la Universidad de Oviedo, Madrid, CSIC, 2008. 
Rahi, Arturo: La moneda y los bancos en el Paraguay, Asunción, Ediciones Comuneros, 1997.

Riquer i Permanyer, Borja de: Francesc Cambó: home de negocis i empresari cultural, Mataró, Caixa Laietana, 2005.

Riquer i Permanyer, Borja de: Francesc Cambó: entre la monarquía i la república (1930-1932): com les memòries s'acomoden a les circumstàncies polítiques, Barcelona, Base, 2007.

Riquer i Permanyer, Borja de: Alfons XIII i Francesc Cambó, unes relacions difícils, Barcelona, Reial Acadèmia de Bones Lletres, 2008.

Rodrigo Alharilla, Martín: Los marqueses de Comillas, 1817-1925. Antonio y Claudio López, Madrid, LID, 2001.

Santos, Carlos R.: La República del Paraguay, Asunción, Talleres Nacionales de H. Kraus, 1897.

Scavone Yegros, Ricardo: Las relaciones entre el Paraguay y Bolivia en el siglo XIX, Asunción, Servilibro, 2004.

Scavone Yegros, Ricardo: «Guerra internacional y confrontaciones políticas (1920-1954)», en Telesca, Ignacio (coord.), Historia del Paraguay, Asunción, Taurus, 2010, 225-264.

Scavone Yegros, Ricardo y Brezzo, Liliana: Historia de las Relaciones Internacionales del Paraguay, Asunción, El Lector, 2010.

Sellés i Quintana, Magda: Una aproximació a la història de la societat d'estudis econòmics, Barcelona, Publicacions de l'Abadia de Montserrat-Biblioteca Serra D'Or, 2002.

Sepúlveda, Isidro: El sueño de la Madre Patria. Hispanoamericanismo y nacionalismo, Madrid, Marcial Pons, 2005.

Ucelay-Da Cal, Enric: El imperialismo catalán. Prat de la Riba, Cambó, D’Ors y la conquista moral de España, Barcelona, Edhasa, 2003.

Vehils, Rafael: Los fundamentos del americanismo español y la misión oficial de la Casa de América de Barcelona, Corrientes-Buenos Aires, Editorial E. Díaz (hijo), 1913.

Vehils, Rafael: Memorándum Reservado sobre fomento de relaciones de España con las Repúblicas de América, Barcelona, Tipografía La Académica de Serra Hermanos y Russell, 1915.

Verón, Luis: La ciudad de Asunción y sus intendentes, Asunción, El Lector, 2011. 